\title{
On Fitotoxicity and Possibility to Utilize Boiling Lye During Grass Cellulose Producion by Innovative Methods
}

\author{
Gilyaziv Minnegali Yusupovich \\ Dr.sc.agr., professor \\ Kazan State Agricultural University \\ Kazan, Russian Federation \\ e-mail: mingilyazov@yandex.ru
}

\author{
Fashutdinov Fannur Shuakatovich \\ candidiate sc. agr., associate professor \\ Kazan State Agricultural University \\ Kazan, Russian Federation \\ e-mail: ditto1961t@mail.ru
}

\author{
Minikaev Ragat Vagizovich \\ candidiate sc. agr., associate professor \\ Kazan State Agricultural University \\ Kazan, Russian Federation \\ e-mail: ragat@mail.ru
}

\begin{abstract}
New grass cellulose production technology from straw has been developed in Republic of Tatarstan. It can give a new impact to steady development of agriculture areas. Fitotoxicity of boiling lye during grass cellulose production has been studied. This allows grounding ways of its utilization in agriculture. Model experiments in gray forest soil with two types of boiling lye have been conducted. Oat, spring rape, and oil radish seeds died during direct contacting with boiling lye, but highly diluted boiling lye solutions enhanced the oat, oil radish germination. Influence of increasing lye doses on the initial plants growth has been determined depending on gray forest soil acidity degree: when boiling lye dose increases the number of oil radish springs increase on highly acidic soil and decrease on neutral soil.
\end{abstract}

Keywords-Grass cellulose, boiling lye fototoxicity, gray forest soil, model experiment, germinative capacity, springs weight, oat, oil radish, spring rape

\section{INTRODUCTION}

The first condition for steady development of agricultural areas is agricultural economy diversification that is widening the range of agricultural products in order to get economical profit, providing employment and raising agricultural population standards of living. The other important condition for steady agricultural areas development is ecological production and expanded reproduction of soil quality.

Both problems can be solved with an innovative cellulose production technology from grass cellulose, exactly from straw.

Cellulose is one of the most important products used in national economy. It is used for paper, cardboard, different artificial fibers - hydrocellulose (viscose fiber, copper ammonia fiber) and cellulose (acetated and triacetate), films (cellophane), plastics and lacquers. Natural cellulose fibers (cotton, bast fibers), and artificial fibers are widely used in textile industry $[2,13]$.

Hard wood is hardly suitable for cellulose production [14] that is why it is mostly produced from pine wood which is decreasing drastically [1]

These conditions necessitate cellulose production from hard wood and grass. Grass cellulose production is more perspective for many countries as grass production exceeds wood production. That is why countries with wood deficit and excess vegetation, such as China, India, Holland, Spain, France, the USA (southern states) and Latin America countries increased technologies of grass cellulose production. But to some extend these technologies are similar to cellulose production with all its drawbacks [8]

All existing methods of wood cellulose production are ecologically unfriendly, create problems at purification plants, have a heavy toll on the environment and people health. The vivid example is Baikal pulp and paper plant, which is closed nowadays. In this context, a new technology of grass cellulose production, by the scientific group of OJSC "SRIneftpromchim" (Russian Federation, republic of Tatarstan, Kazan) directed by O. K. Nugmanov and N. A. Lebedev [8-12].

\section{PRoBlem STATEMENT}

The new technology of grass semicellulose production (short technological cycle) and cellulose (full technological cycle), has no drawbacks of the previous technology. This technology is based on the multifunctional continuous reactor, which simultaneously "boils" the straw, extracts woody stem 
part (delignification) and blends cellulose fiber. Grass cellulose is produced without catalysis at atmospheric pressure and temperature $1000 \mathrm{C}$. At decantation, flushing, and pressing stages continuous action centrifuges are used, for bleaching hydrogen peroxide is used and for drying of fiber microwave equipment is used $[8,9]$.

This technology decreases negative impact of pulp and paper industry on the environment and human health, provides possibilities for agriculture development.

Using straw as industrial raw material can boost marketability of agriculture. Unfortunately, low marketability of present agriculture is one of the factors hindering agriculture development [6]. In 2008-2013 In republic of Tatarstan agriculture marketability was less $40 \%$ and annually about 100 billion rubles of agricultural products were kept in the industry which is inacceptable.

\section{RESEARCH QUESTIONS}

From the ecological point of view the advantages of the new technology of grass cellulose production are: preserving forest resources of the country, decreasing water consumption for the industry by 5 times; abandoning chlorinated derivatives and buffer sulphurous catalysis and gas emissions [8]. At the same time there is no information about toxicity of wastes from new technology of cellulose production (boiling lye) there are no ways of its utilization. Those were the motives for our research.

\section{PURPOSE OF THE STUDY}

The purpose of the study is estimating fitotoxicity of grass cellulose boiling lye doses, produced with the new technology, by seed germinating capacity; crop springs weight, which can be the ground for boiling lye utilization via soil application.

\section{RESEARCH METHODS}

The objects of the research are two types of boiling lye (№1 is exhausted lye of five-time recycle of rape cellulose production and № 2 is outflow after rape cellulose hot wash).

North part gray forest soil of republic Tatarstan (RT) was used in model experiments. This part is located in the middle of the Volga river flow and down part of the Kama, in steepe and forest -steepe zones of the Eastern part of Russian plain. Geographic position of the republic is determined by coordinates 53058' - 56o39' north latitude and 47o15' - 54o 18 ' east longitude. [7].

Gray forest soil is the most expanded in this part of the region and RT. Soil for model experiments was taken from Pestrechinsk agricultural enterprises of RT and analyzed for exchange acidity. All the analyzed soils were classified into three groups according to salt extract acidity (blocks). Humus content in the top soil is from 2.2 to $3.1 \%$, that is all the soils in the experiment are with low humus content. Phosphorus and potassium active forms content varied in the range 118147 and 124-156 correspondingly (fourth group of availability). The main difference between these soils is in acid-base properties. The first group contains soils with salt extraction acidity from 4.1 to 4.5 . The second group is with 4.6-5.0. Correspondingly, the 1st and 2nd block soils are highly acidic and medium acidic and need calcification. The $3 \mathrm{~d}$ block soil is neutral according to acidity degree (salt extraction acidity is more than 6.0), and it does not need calcination.

The soils were analyzed in laboratories of FSBI Organization of Central Asian Cooperation "Tatar" and AgroChemistry and Soil Science Board of Kazan SAU. Soil agrochemical parameters were determined by common methods: moisture content according to GOST Standard 28268-89, humus content according to GOST 26213-91, active phosphorus and potassium content by Kirsanov methods modified by CRSI of AS according to GOST 26207 91 , salt extraction preparation and its acidity determination by CRSI of AS according to GOST 26483-85. Correlative regression analysis of experimental data was done according to Dospehov [5] with Statistica ver. 5.5 A for Windows.

\section{FINDINGS}

\section{A. Direct impact of grass cellulose boiling lye on seeds germinating ability}

The study of grass cellulose boiling lye impact on seeds germinating ability of some crops was done according to GOST 12038-84 "Crops. Germinating ability determining methods" in Petri dish on absorbent paper. Direct impact of grass cellulose boiling lye on three crops - oat (Avena sativa), spring rape (Brassica napus) and oil radish (Brassica rapa) was estimated. The direct contact of these crops seeds with both unadulterated boiling lye resulted in seeds death (table. 1).

TABLE I. DEPENDENCE OF SEEDS GERMINATING ABILITY ON BOILING LYE DILUTION IN SEEDS DIRECT IMPACT

\begin{tabular}{|c|c|c|c|c|c|}
\hline \multirow{3}{*}{$\begin{array}{c}\text { Dilution } \\
\text { degree }\end{array}$} & \multirow{3}{*}{$\begin{array}{c}\text { Boiling lye } \\
\text { content, } \\
\%\end{array}$} & \multicolumn{4}{|c|}{ Seeds germinating ability, $\%$} \\
\hline & & \multicolumn{2}{|c|}{$\begin{array}{c}\text { boiling lye } \\
\text { № } 1\end{array}$} & \multicolumn{2}{|c|}{$\begin{array}{c}\text { boiling lye } \\
\text { № } 2\end{array}$} \\
\hline & & $\begin{array}{l}\text { spring } \\
\text { rape }\end{array}$ & oat & oil radish & oat \\
\hline $\begin{array}{c}\text { Water } \\
\text { (control) }\end{array}$ & 0 & $\frac{75}{100}$ & $\frac{83}{100}$ & $\frac{62}{100}$ & $\frac{71}{100}$ \\
\hline $1: 200$ & 0,5 & $\frac{46}{61 *}$ & $\frac{70}{84 *}$ & $\frac{63}{102} *$ & $\frac{82}{115^{*}}$ \\
\hline $1: 100$ & 1 & $\frac{38}{51}$ & $\frac{58}{70}$ & $\frac{69}{111}$ & $\frac{46}{65}$ \\
\hline $1: 50$ & 2 & $\frac{6}{8}$ & $\frac{68}{82}$ & $\frac{66}{106}$ & $\frac{40}{56}$ \\
\hline $1: 20$ & 5 & 0 & $\frac{15}{18}$ & $\frac{59}{95}$ & $\frac{33}{46}$ \\
\hline $1: 10$ & 10 & 0 & 0 & $\frac{34}{55}$ & $\frac{18}{25}$ \\
\hline $1: 5$ & 20 & 0 & 0 & $\frac{18}{29}$ & $\frac{14}{20}$ \\
\hline $1: 1$ & 50 & 0 & 0 & 0 & $\frac{13}{18}$ \\
\hline undiluted lye & 100 & 0 & 0 & 0 & 0 \\
\hline \multicolumn{2}{|c|}{ Correlation coefficient (r) } & -0.85 & -0.94 & -0.93 & -0.67 \\
\hline
\end{tabular}


There is close negative correlation between boiling lye concentration and crops germinating ability $(\mathrm{r}=-0.67 \div 0.94)$. According to the data boiling lye № 1 is more toxic. Boiling lye № 2 if dissolved significantly (1:200 for oat and 1:100 for oil radish) had stimulating impact: oat germinating ability increased by $15 \%$ (200 times dissolution), and oil rape germinating ability increased by $11 \%$ (100 times dissolution). This may evidence the presence of some substance in boiling lye № 2 from grass raw material during boiling which stimulate seeds germination.

Among the tested crops, according to their germinating ability, oat is the most resistant to the negative impact of boiling lye. It is clearly seen during impact of boiling lye № 1: in contact with $5 \%$ solution $(1: 20) 15 \%$ of oat seeds preserved their germinating ability, while spring rape seeds died. Nearly the same response of oat seeds and oil radish is with contact weakly dissolved (1:1) boiling lye № 2: oil rape death, while $13 \%$ of oat seeds kept their germinating ability.

Changes in crops germinating ability in direct contact with boiling lye, evidence the presence of substances stimulating and depressing crops germinating ability.

\section{B. Direct impact of grass cellulose boiling lye increasing doses on gray forest soil toxicity}

Fitotoxicity estimation of gray forest soil after introduction of different doses of boiling lye was done accourding to GOST R ISO 22030-2009, that is according to oat (Avena sativa) initial and oil radish (Brassica rapa) growth. Grey forest soil has been composted with increasing doses (from 1.67 to $267 \mathrm{ml} / \mathrm{kg}$ of soil) of boiling lye № 2 for 3 months. As it has been mentioned, soil phases according to three types of acidity (highly acidic, medium acidic, neutral), were classified according to the analysis results (determining exchange acidity by potentiometer method) more than 150 soil samples of Pestrechinsk region of RT enterprises.

Air dry soil weight in vessels 200 g. Optimum water content, equal $60 \%$ of absolute moisture capacity, was supported by weight water application both during composting and before and after crops planting. The experiment was repeated four times.

After month composting of grey forest soil the first experiment crop - oil radish was planted. 10 full seeds were planted into every dish. The weight and mass of germinating seeds analysis was done in 2 weeks after planting. Oil radish spring tops control showed that the impact character of boiling lye increasing doses was greatly conditioned by gray forest acidity degree (pic. 1). On the highly acidic gray forest soil the increasing doses of boiling lye had a positive impact on the total weight of oil radish springs $(\mathrm{r}=0.40)$. According to Shaddock scale close correlation of spring weight to lye doses on the highly acidic soils was moderate. On medium acidic soils there was no positive influence and there appeared suppressive action, though negative impact of increasing lye doses.

Is not significant statistically $(\mathrm{r}=-0.07)$. Introduction of boiling lye into neutral soil resulted in significant suppression of top springs accumulation $(\mathrm{r}=-0.55)$. We can suppose that boiling lye introduction into soils is advisable on highly acidic soils.
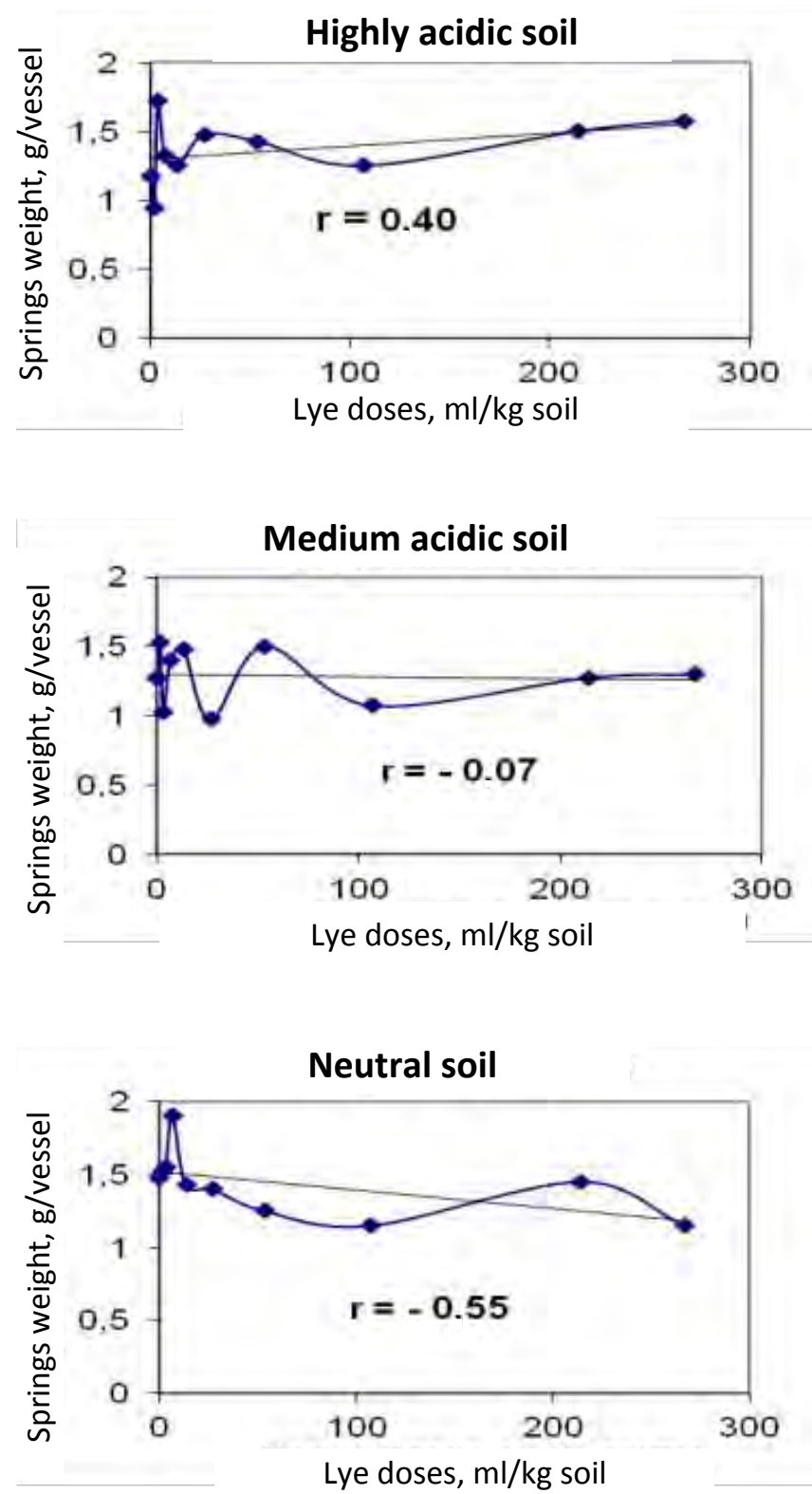

Fig. 1. Correlation of total springs weight of oil radish on boiling lye doses № 2 on the gray forest soil depending on its original acidity

The same conclusion can be done about oil radish (pic. 2). According to this criteria positive impact of increasing doses of lye on highly acidic soils was weak $(r=0.17)$, and on medium acidic soil there appears a negative impact of lye $(\mathrm{r}=$ - 0.42). Much more negative impact on oil radish springs was on neutral soils $(\mathrm{r}=-0.63)$.

Another experimental crop - oat - was planted after 2 two months from starting composting. The data evidence that oat reaction to increasing lye doses differed from oat response to lye, though the determining role of acid-base properties was distinct (pic. 3). According to the seeds weight and number, 
oat was the most resistant crop to negative impact of boiling lay. Even maximum lye dose did not influence oat growth (267 ml/kg soil) negatively.
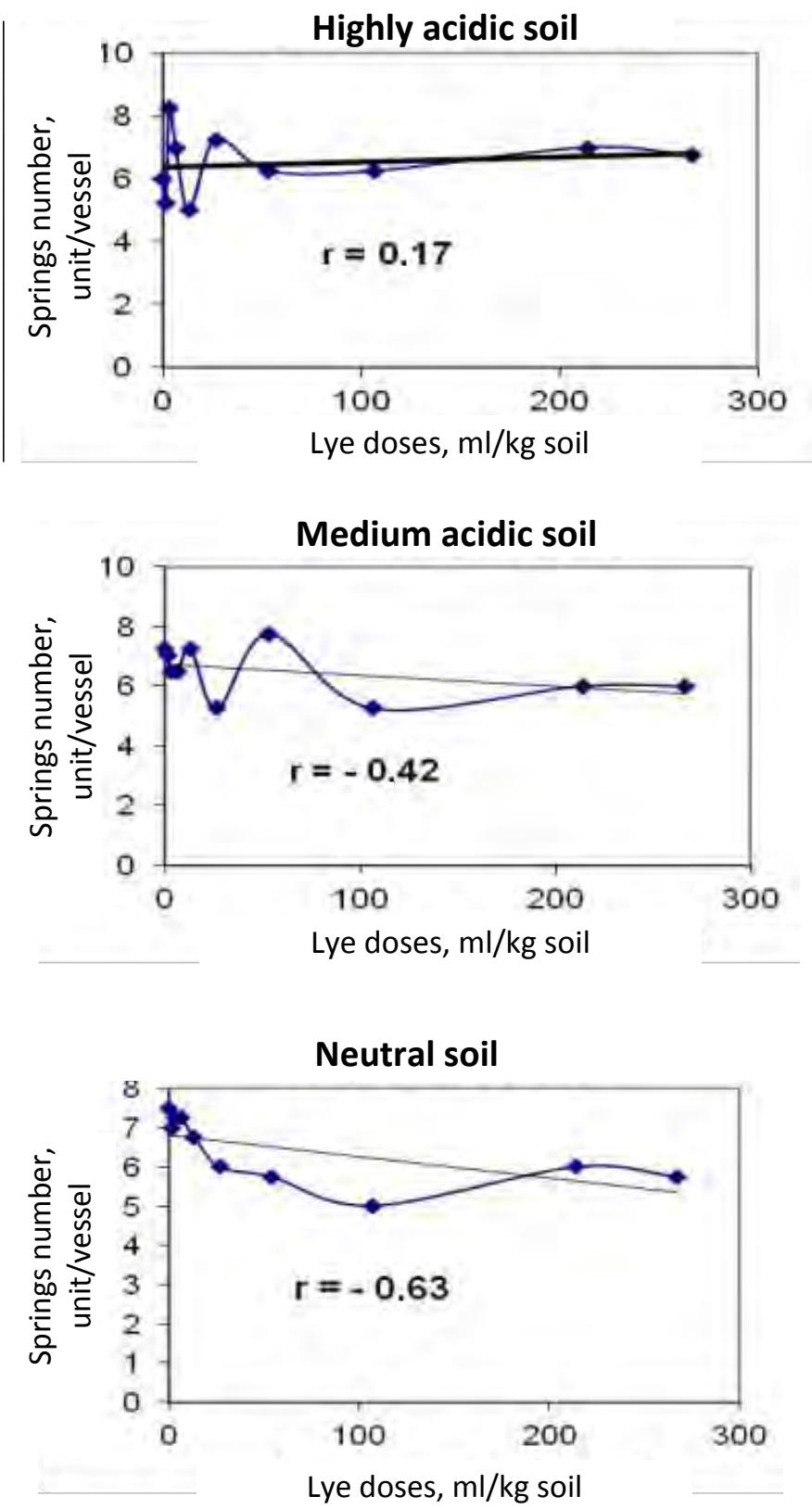

Fig. 2. Correlation of oil radish springs on boiling lye doses № 2 on gray forest soil depending on initial soil acidity

On all soil groups differing by their acidity correlation coefficients between weight and number of springs on one side and lye doses on the other side have positive influence. Despite this, acid-base soil properties are very significant. Correlation between total oat springs weight on increasing lye doses on highly acidic soils was very close $(r=0.82)$. On medium and neutral acidic soils dependence of oat springs weight on increasing lye doses decreased significantly: correlation coefficients between these values were 0.68 and 0.17 correspondingly.
Hence, the crops response at first stage of growth on boiling lye doses was greatly determined both by crop biological characteristics and acid-base soil properties. Response difference on increasing lye doses of two tested crops should be studied further. This fact is difficult to explain from the point of view of traditional classification of crops to environment reaction as oat and radish belong to the same group of crops, with weak sensibility to soil acidity.
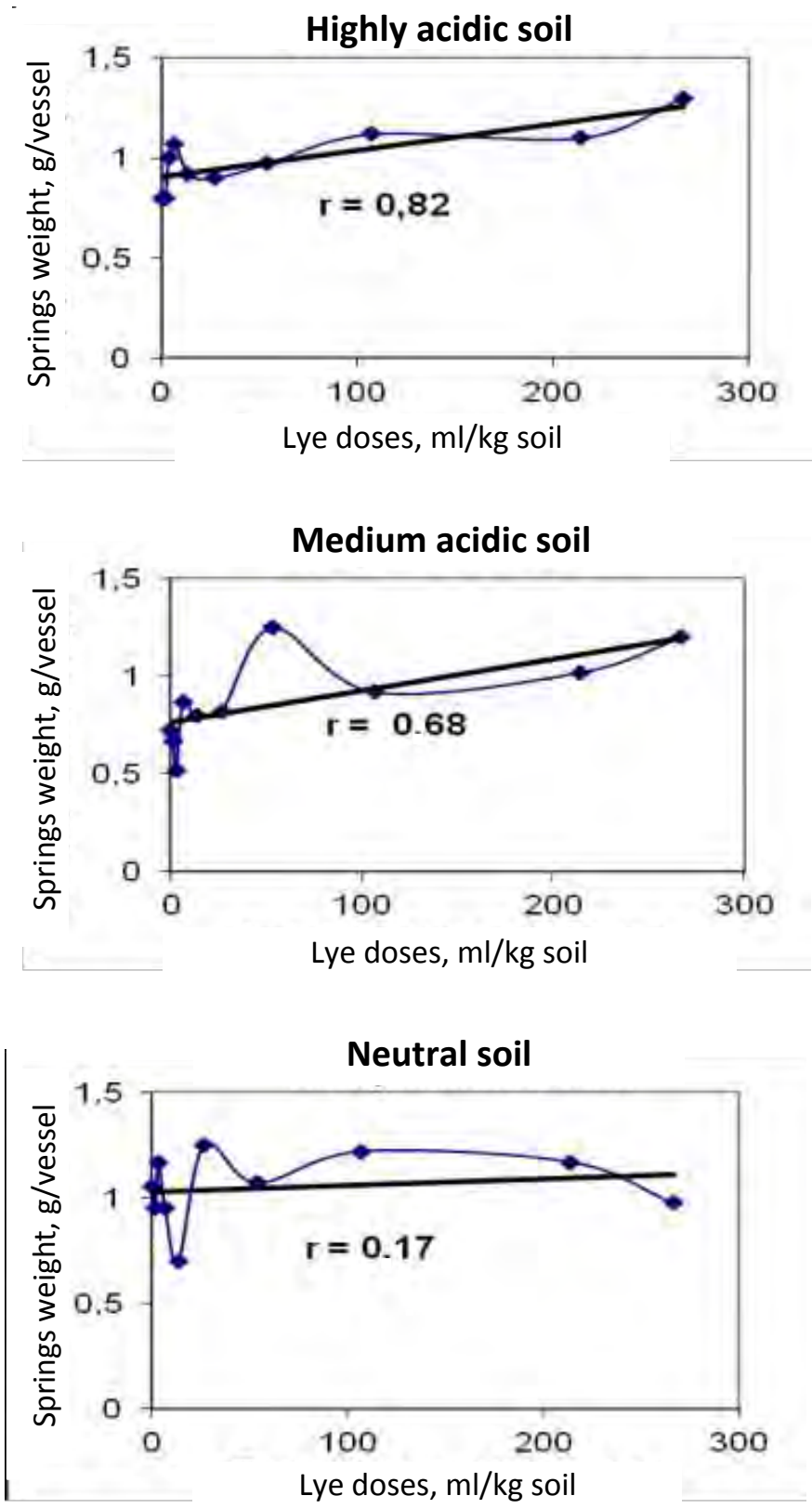

Fig. 3. Correlation of oat springs on boiling lye doses № 2 on gray forest soil depending on initial soil acidity

\section{CONCLUSION}

It has been determined that there is close negative correlation between boiling lye concentration and tested crops generating ability $(\mathrm{r}=-0.67 \div 0.94)$. At the same time highly 
dissolved boiling lye solutions somewhat increased seeds generating ability and springs weight. The influence of increasing boiling lye doses on the initial plants growth is greatly determined by acidity degree of gray forest soil: if on highly acidic soils increasing lye doses had positive impact on oil radish springs weight $(\mathrm{r}=0.40)$, then on neutral soils there was a significant top springs weight decrease $(\mathrm{r}=-0.55)$. Perhaps, due to the presence of some substances in boiling lye negative impact of high acidity on oat is not as clear as in relation to oil radish. Consequently, further studies should be conducted on the wider range of crops, as plants reaction, even close in relation to soil acidity, differ significantly. In general positive influence of boiling lye on the initial growth of crops on highly acidic and medium acidic soils allows its utilization as a chemical ameliorant of acid soils.

\section{Acknowledgment}

The authors express their sincere gratitude to the main creators of the new technology of grass cellulose production from straw Candidate of chemical science, the Head of the department OJSC "SRIneftepromhim" Oleg Kagarmanovich Nugmanov and Candidate of science, director of OJSC "SRIneftepromhim" Nikolay Alexeevich Lebedev for providing boiling lye and financial support for the experiments, as well as Doctor of agricultural sciences, corresponding member of Academy of Science of Respublic of Tatarstan Ilshat Ahatovich Gaisin for help in conducting agro-chemical soil analysis..

\section{References}

[1] A.V. Vurasko, S.Yu., Men'shikov, I. Vedeneev, N. Sobacheva, "Sulfur free method of cellulose production", retrieved from: http://www.newchemistry.ru/printletter.php? n_id=5478

[2] B. D. Bogomolov, "Wood chemistry and principles of high-molecular compounds chemistry", Moscow: Chemistry, 1973, p.400.

[3] I.H. Gabdrahmanov et al, "Contemporary issues of highly acidic soils calcination in Republic of Tatarstan and ways of their solution", Kazan, 2008, p. 130.

[4] I.D. Davlyatshin, M.Yu. Gilyazov, A.A. Lukmanov et al, "Guidebook for agrochemist of the Republic of Tatarstan", Kazan: ID MeDDok, 2013 , p. 300.

[5] B.A. Dospehov, "Methods of experiment", 5th edition, Moscow: Agropromizdat, 1985, p. 351.

[6] Republican Government of Tatrstan, "Conception and methodology of steady development of agrarian complex in Republic of Tatarstan", Kazan: Kazan SAU, 2014, p. 100.

[7] M.R. Mustafin, R.G. Huzeev, "All about Tatarstan (EconomicalGeographical reference book)", Kazan:Tat. Publishing house, 1994, p. 164.

[8] O .Nugmanov, N. Lebedev, "Cellulose. The beginning of our era. Tatarstan introduces an innovative technology for cellulose production on Russian and World market", The Chemical Journal, December 2009 pp. 30-33.

[9] O. Nugmanov, N. Lebedev, R. Yarullin, "Grass cellulose in Russian regions", The Chemical Journal, Septmber 2012, pp. 30-32.

[10] O.K. Nugmanov, N.P. Grigorieva, N.A. Lebedev, V.N. Khlebnikov, R.N. Yarullin, "Methods of cellulose production", Patent (RF) №2343241, 2009, No. 1, p. 6.

[11] O.K. Nugmanov, N.P. Grigorieva, N.I. Gainulling, N.A. Lebedev, "Methods of cellulose production”, Patent (RF) №2378432, 2010, No. 1, p. 6.

[12] O.K. Nugmanov, N.P. Grigorieva, D.S. Nusinovach, N.A. Lebedev, "Methods of cellulose production", Patent (RF) №2413808, 2011, No. 7, p. 6 .

[13] Z.A Rogovin, "Cellulose chemistry”, Moscow: Chemistry, 1972, p. 520.

[14] "Russian pulp-cellulose industry. Part one. Cellulose production", online factbook, retrieved from: http:/geo.1september.ru/2005/06/23.htm. 